\title{
Hypertension and cardiovascular risk factor management in a multi-ethnic cohort of adults with CKD: a cross sectional study in general practice
}

\author{
Edianne Monique Carpio ${ }^{1} \cdot$ Mark Ashworth $^{1} \cdot$ Elham Asgari $^{2} \cdot$ Catriona Shaw $^{3} \cdot$ Patricia Schartau $^{4} \cdot$ Stevo Durbaba $^{1}$. \\ Dorothea Nitsch ${ }^{5} \cdot$ Mariam Molokhia $^{1}$
}

Received: 17 May 2021 / Accepted: 22 August 2021 / Published online: 16 November 2021

(c) The Author(s) 2021

\begin{abstract}
Background Hypertension, especially if poorly controlled, is a key determinant of chronic kidney disease (CKD) development and progression to end stage renal disease (ESRD).

Aim To assess hypertension and risk factor management, and determinants of systolic blood pressure control in individuals with CKD and hypertension.

Design and setting Cross-sectional survey using primary care electronic health records from 47/49 general practice clinics in South London.

Methods Known effective interventions, management of hypertension and cardiovascular disease (CVD) risk in patients with CKD Stages 3-5 were investigated. Multivariable logistic regression analysis examined the association of demographic factors, comorbidities, deprivation, and CKD coding, with systolic blood pressure control status as outcome. Individuals with diabetes were excluded.

Results Adults with CKD Stages 3-5 and hypertension represented 4131/286,162 (1.4\%) of the total population; 1984 (48\%) of these individuals had undiagnosed CKD without a recorded CKD clinical code. Hypertension was undiagnosed in $25 \%$ of the total Lambeth population, and in patients with CKD without diagnosed hypertension, $23.0 \%$ had systolic blood pressure $>140 \mathrm{mmHg}$ compared with $39.8 \%$ hypertensives, $\mathrm{p}<0.001$. Multivariable logistic regression revealed that factors associated with improved systolic blood pressure control in CKD included diastolic blood pressure control, serious mental illness, history of cardiovascular co-morbidities, CKD diagnostic coding, and age $<60$ years. African ethnicity and obesity were associated with poorer systolic blood pressure control.

Conclusion We found both underdiagnosed CKD and underdiagnosed hypertension in patients with CKD. The poor systolic blood pressure control in older age groups $\geq 60$ years and in Black African or obese individuals is clinically important as these groups are at increased risk of mortality for cardiovascular diseases.
\end{abstract}

Mariam Molokhia

mariam.molokhia@kcl.ac.uk

1 Department of Population Health Sciences, King's College

London, London, England

2 Renal Department, Guy's and St Thomas' NHS Foundation Trust, London, England

3 Renal Department, King's College Hospital, London, England

4 Department of Primary Care \& Population Health, Institute of Epidemiology \& Health, University College London, London, England

5 Department of Non-Communicable Disease Epidemiology, London School of Hygiene \& Tropical Medicine, London, England 


\section{Graphic abstract}

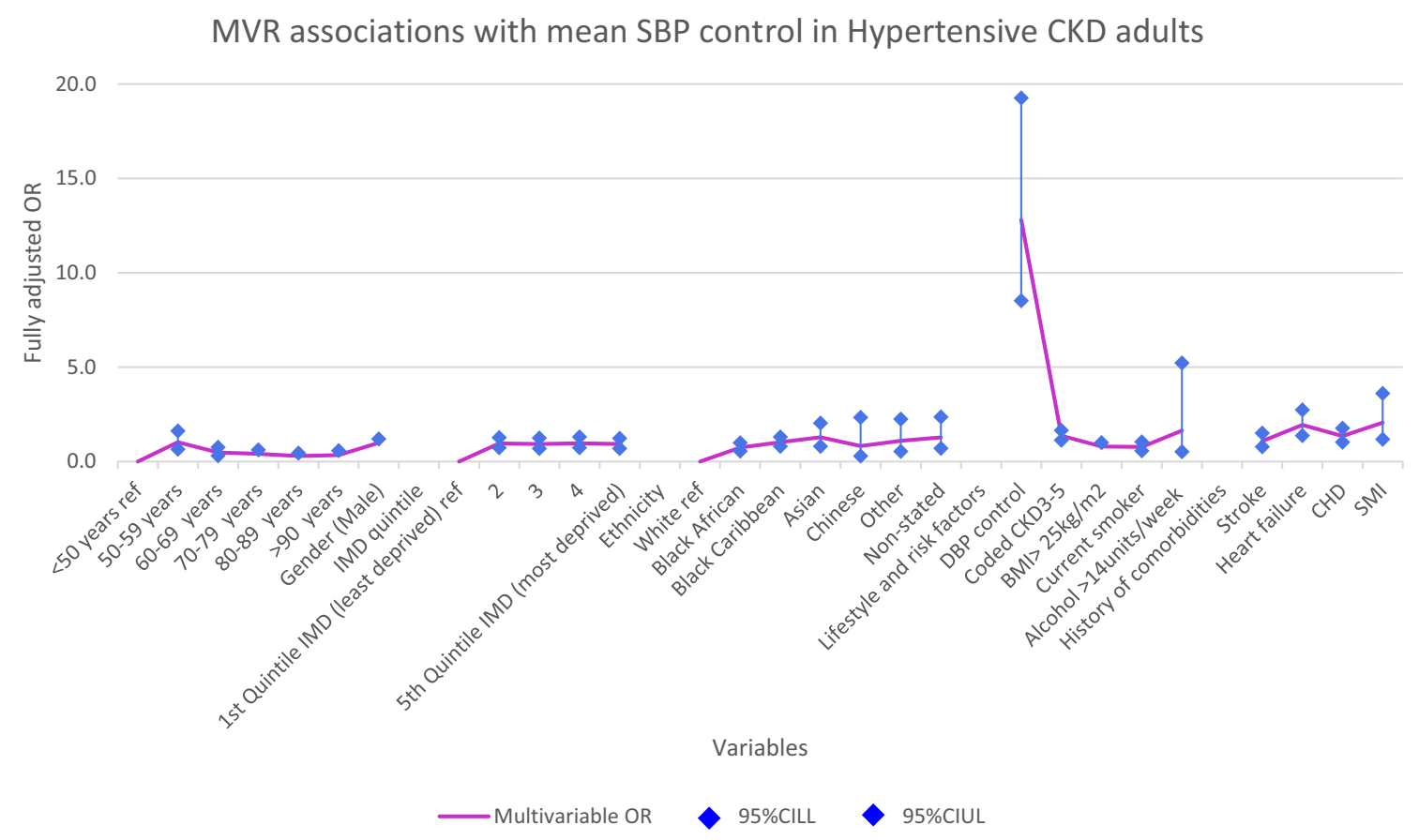

Keywords CKD $\cdot$ Hypertension · Ethnicity $\cdot$ CVD $\cdot$ Undiagnosed $\cdot$ African

\section{Abbreviations}

ACEI

ACR

AOR

ARB

BMI

$\mathrm{BP}$

$\mathrm{CCB}$

CCG

CHD

CKD

CVD

COXIB

DBP

(e)GFR

EHR

ESRD

GFR

HF

HT

IMD

$\mathrm{KCL}$

KDIGO
Angiotensin-converting-enzyme inhibitor drug

Albumin creatinine ratio

Adjusted odds ratio

Angiotensin-receptor blocker

Body mass index

Blood pressure

Calcium channel blocker

Clinical Commissioning Group

Coronary heart disease

Chronic kidney disease

Cardiovascular disease

A type of non-steroidal anti-inflammatory drug (NSAID) that directly targets cyclooxygenase-2 COX-2, an enzyme responsible for inflammation and pain

Diastolic blood pressure

(Estimated) glomerular filtration rate

Electronic health record

End-stage renal disease

Glomerular filtration rate

Heart failure

Hypertension

Index of multiple deprivation

King's College London

Kidney Disease: Improving Global Outcomes
LDN Lambeth DataNet

MDRD Modification of Diet in Renal Disease

MPH Master of Public Health

MVR Multivariable logistic regression

NA-CKD Normoalbuminuric chronic kidney disease

NCKDA National CKD audit

NICE National Institute for Health and Care

Excellence

NSAIDS Non-steroidal anti-inflammatory medication

QOF Quality Outcome Framework

READ A coded thesaurus of clinical terms. There are two versions: version 2 (v2) and version 3 (CTV3 or v3)

RRT Renal replacement therapy

SBP Systolic blood pressure

SMI Serious mental illness

WHO World Health Organization

\section{Introduction}

\section{CKD and hypertension}

The diagnosis of chronic kidney disease (CKD) is mainly based on estimated glomerular filtration rate (eGFR) $<60 \mathrm{ml} / \mathrm{min} / 1.73 \mathrm{~m}^{2}$ for at least 3 months, even if 
the broader definition includes all persistent alterations of renal morphology and of blood or urine composition [1]. Key risk factors for CKD include hypertension, cardiovascular disease (CVD), and diabetes [2], and CKD is associated with significant morbidity and mortality, in particular in these groups [2,3].

CKD is common in England, an estimated 6.1\% people aged $16 \geq$ years are living with CKD (defined as eGFR $<60 \mathrm{ml} / \mathrm{min} / 1.73 \mathrm{~m}^{2}$ ), and this is projected to include 3.2 million people in 2021 [4]. The treatment of CKD Stage 3-5 poses a considerable financial burden, and the lifetime the lost health-related quality of life is estimated as £7.18 billion in England [5]. This includes the high cost of renal replacement therapy (RRT) for survivors with end-stage renal disease and cardiovascular disease complications. In UK primary care, the Quality and Outcomes Framework (QOF) incentivises maintaining a CKD register with regular renal monitoring, which now includes classification of GFR categories "G3a to G5" (based on eGFR), although recommendations for BP targets $<140 / 90$, and Albumin Creatinine Ratio (ACR) testing have been dropped [6]. However, persistent albuminuria prevalence (elevated urinary ACR with normal eGFR) in CKD stages 1 and 2 is estimated as high as 10\% [7] and is associated with a doubling in mortality risk [8].

Data from the national CKD audit (NCKDA) report suggest that individuals with CKD and hypertension may not be well managed [9]. However, the NCKDA (gathering a largely White population) was unable to examine ethnic inequalities. The NCKDA audit suggests that $30 \%$ of CKD is undiagnosed (i.e. not formally coded), especially at younger ages, resulting in poorer quality of care [9]. The National Institute for Health and Care Excellence (NICE) Guidelines recommend regular renal function monitoring for individuals with hypertension, diabetes, and cardiovascular disease (CVD). In these groups, CKD is therefore more likely to be detected, as this is supported by QOF incentives for disease monitoring, including renal function.

Hypertension, especially if poorly controlled $[10,11]$ is a key determinant of CKD development and progression, and is present in the majority of people with diagnosed CKD $(89 \%)$ in England [12, 13]. Antihypertensive medications, such as angiotensin receptor blockers (ARBs) and angiotensin-converting-enzyme inhibitors (ACEIs), are also currently recommended by the NICE (National Institute for Health and Care Excellence) guidelines as first line management for proteinuric CKD and for non proteinuric CKD in patients with hypertension [14], although recent findings suggest that these medications are under-prescribed $[10,15]$.

Known markers of CKD progression (measured by eGFR decline) include proteinuria [16-18], and blood pressure control has been shown to reduce proteinuria, and delay eGFR decline [19-21]. Blood pressure control has been reported to be poor in patients with CKD Stage 3 [15], but little is known in later stages of CKD. Recognised risk factors for CKD include age, sex, ethnicity, hypertension, diabetes, cardiovascular disease, smoking, obesity and nonsteroidal anti-inflammatory drug (NSAID) use [22, 23].

Patients with CKD and hypertension alone are managed and captured differently under Quality Outcome Framework, compared to those with CKD and diabetes. The NCKDA report has previously published differences in management by diabetes status. To our knowledge, there has been limited focus on the management of CKD in the UK by hypertension status. This study aimed to assess hypertension and risk factor management, and determinants of systolic blood pressure (SBP) control in individuals with CKD and hypertension HT.

\section{Methods}

\section{Study design}

Cross-sectional study of non-diabetic individuals with CKD.

\section{Data sources}

We used a dataset derived from general practice electronic health records (EHRs), Lambeth DataNet (LDN), south London, extracted from patient records from 1990 until October 2013. LDN contains clinical data, prescription data, laboratory data, and demographic information, such as age, sex, and ethnicity, based on categories of the UK 2001 census, CVD risk factors and co-morbidities. We investigated demographic factors, comorbidities, and other interventions considered as potentially effective, in a population identified as having CKD Stage 3-5, with and without hypertension.

\section{Study population}

Individuals with CKD Stage 3-5 (defined based on the criteria reported below). Patients with diabetes were excluded, as they have different profiles of proteinuria and cardiovascular risk [24]. The study was carried out using anonymised data from patients registered in 47/49 general practices, in an ethnically and socially diverse population of 286,162 adults ( $\geq 18$ years), followed-up in Lambeth, south London.

\section{Identification of CKD}

Our CKD Stage 3-5 cohort comprised diagnosed and undiagnosed cases. Diagnosed CKD status was determined using QOF incentive scheme CKD descriptive codes, plus codes for dialysis or renal transplantation (Appendix Table S1). 
Table 1 Prevalence of CVD risk factors and effective risk factor interventions characteristics in patients with CKD by hypertensive status

\begin{tabular}{|c|c|c|c|}
\hline \multirow[t]{2}{*}{ Variables } & CKD and $\mathrm{HT}$ & $\begin{array}{l}\text { CKD without acknowl- } \\
\text { edged hypertension }\end{array}$ & \multirow[t]{2}{*}{$p$-value } \\
\hline & $\mathrm{N}(\mathrm{Col} \%)$ & $\mathrm{N}(\mathrm{Col} \%)$ & \\
\hline CKD stage $\geq 3$ & $4131(16.5)$ & $2657(1.1)$ & $* *$ \\
\hline \multicolumn{4}{|l|}{ Sex } \\
\hline Female & $2388(57.8)$ & $1556(58.6)$ & \multirow[t]{2}{*}{$\mathrm{P}>0.05$} \\
\hline Male & $1743(42.2)$ & $1101(41.4)$ & \\
\hline \multicolumn{4}{|l|}{ Age (years) } \\
\hline$<50$ & $346(8.4)$ & $720(27.1)$ & \multirow[t]{6}{*}{$* *$} \\
\hline $50-59$ & $568(13.8)$ & $642(24.2)$ & \\
\hline $60-69$ & $620(15.0)$ & $480(18.1)$ & \\
\hline $70-79$ & $1,127(27.3)$ & $406(15.3)$ & \\
\hline $80-89$ & $1,149(27.8)$ & $322(12.1)$ & \\
\hline$>90$ & $321(7.8)$ & $87(3.3)$ & \\
\hline \multicolumn{4}{|l|}{$\operatorname{BMI}\left(\mathrm{kg} / \mathrm{m}^{2}\right)$} \\
\hline Normal or below normal (below $25 \mathrm{~kg} / \mathrm{m}^{2}$ ) & $1027(24.9)$ & 778 (31.9) & \multirow[t]{6}{*}{$* *$} \\
\hline Overweight $\left(25.0-29.9 \mathrm{~kg} / \mathrm{m}^{2}\right)$ & $1,452(35.2)$ & $796(30.0)$ & \\
\hline Obesity grade I (30.0-34.9 kg/m²) & $858(20.8)$ & $412(15.5)$ & \\
\hline Obesity grade II $\left(35.0-39.9 \mathrm{~kg} / \mathrm{m}^{2}\right)$ & $333(8.1)$ & $147(5.5)$ & \\
\hline Obesity grade III $\left(\geq 40 \mathrm{~kg} / \mathrm{m}^{2}\right)$ & $149(3.6)$ & $57(2.1)$ & \\
\hline Missing value & $312(7.6)$ & $399(15.0)$ & \\
\hline \multicolumn{4}{|l|}{$\begin{array}{l}\text { Index of Multiple Deprivation } 2015 \text { (IMD) } \\
\text { Quintile ( } \% \text { coded) }\end{array}$} \\
\hline 1 (least deprived) & $962(23.3)$ & $623(23.5)$ & \multirow[t]{6}{*}{$\mathrm{P}>0.05$} \\
\hline 2 & $915(22.2)$ & $528(19.1)$ & \\
\hline 3 & $697(16.9)$ & $463(17.4)$ & \\
\hline 4 & $767(18.6)$ & $524(19.7)$ & \\
\hline 5 & $788(19.1)$ & $515(19.4)$ & \\
\hline Missing & $2(0.05)$ & $4(0.15)$ & \\
\hline \multicolumn{4}{|l|}{ Ethnicity } \\
\hline European & $1,878(45.5)$ & $1,141(42.9)$ & \multirow[t]{8}{*}{$* *$} \\
\hline Black African & $662(16.0)$ & $421(15.8)$ & \\
\hline Black Caribbean & $879(21.3)$ & $522(19.7)$ & \\
\hline South Asian & $174(4.2)$ & $109(4.1)$ & \\
\hline Chinese & $29(0.7)$ & $9(0.3)$ & \\
\hline Other ethnicity & $66(1.6)$ & $58(2.2)$ & \\
\hline Non-stated & $94(2.3)$ & $69(2.6)$ & \\
\hline Missing & $349(8.5)$ & $328(12.3)$ & \\
\hline \multicolumn{4}{|l|}{ History of comorbidities } \\
\hline Previous stroke & $342(8.2)$ & $61(2.3)$ & $* *$ \\
\hline Cancer & $37(0.9)$ & $31(1.2)$ & $\mathrm{P}>0.05$ \\
\hline Coronary Heart Disease, CHD & $602(14.6)$ & $193(7.3)$ & $* *$ \\
\hline Serious mental illness, SMI & $164(4.0)$ & $142(5.3)$ & $*$ \\
\hline Heart failure & $345(8.3)$ & $100(3.7)$ & $* *$ \\
\hline Mean SBP $<140 \mathrm{mmHg}$ & $1,522(60.2)$ & $472(77.0)$ & $* *$ \\
\hline Mean DBP < $90 \mathrm{mmHg}$ & $2,278(90.1)$ & $576(94.0)$ & $*$ \\
\hline \multicolumn{4}{|l|}{ BMI $\left(\mathrm{kg} / \mathrm{m}^{2}\right)$} \\
\hline $\mathrm{BMI}>25 \mathrm{~kg} / \mathrm{m}^{2}$ & $2,792(73.1)$ & $1,412(62.5)$ & $* *$ \\
\hline Current or ex-smoker & $465(11.3)$ & $464(17.6)$ & $* *$ \\
\hline Alcohol > 14 units/week & $29(0.70)$ & $26(1.0)$ & $\mathrm{P}>0.05$ \\
\hline \multicolumn{4}{|l|}{ Prescribed treatments } \\
\hline NSAIDs & $991(24.0)$ & $780(29.4)$ & $* *$ \\
\hline
\end{tabular}


Table 1 (continued)

\begin{tabular}{llll}
\hline Variables & CKD and HT & $\begin{array}{l}\text { CKD without acknowl- } \\
\text { edged hypertension } \\
\mathrm{N}(\mathrm{Col} \%)\end{array}$ & $p$-value \\
\hline COXIBs & $\mathrm{N}(\mathrm{Col} \%)$ & $12(0.5)$ & $\mathrm{P}>0.05$ \\
ACEIs/ARBs & $16(0.4)$ & $335(12.6)$ & $* *$ \\
Beta-blockers & $2,945(71.3)$ & $319(12.0)$ & $* *$ \\
Calcium channel blockers & $1,562(37.8)$ & $167(6.2)$ & $* *$ \\
Diuretics & $2,682(64.9)$ & $145(5.5)$ & $* *$ \\
Statins & $2,191(53.0)$ & $618(23.3)$ & $2,266(54.9)$ \\
\hline
\end{tabular}

CKD includes both diagnosed and undiagnosed CKD Stage 3-5. Patients with diabetes were excluded

$H T$ hypertension, $C H D$ coronary heart disease, $B P$ blood pressure, BMI body mass index, NSAIDs non-steroidal anti-inflammatory drugs, COXIBs COX-2 inhibitors, ACEIs angiotensin-converting-enzyme inhibitors, $A R B s$ angiotensin receptor blockers, $C C B s$ calcium channel blockers, $I M D$ index of multiple deprivation

$* \mathrm{P}<0.05$

$* * \mathrm{P}<0.001$

Non-diagnosed CKD was defined, in the absence of the previous codes, based on the latest two readings $\geq 90$ days apart of eGFR levels $<60 \mathrm{ml} / \mathrm{min} / 1.73 \mathrm{~m}^{2}$ calculated from serum creatinine using the modified four-variable Modification of Diet in Renal Disease (MDRD) equation adjusted for sex and, when appropriate, Black African or Black-Caribbean ethnicity [4]. We excluded miscoded patients, who after use of the ethnic correction factor had an eGFR $>60 \mathrm{ml} /$ $\mathrm{min} / 1.73 \mathrm{~m}^{2}$. Hypertensive CKD is defined as individuals with CKD and hypertension.

\section{Identification of hypertension}

Individuals were defined as hypertensive if they were included In the hypertension Quality Outcome Framework (QOF) register.

\section{Risk factor management}

Risk factor management and CKD prevalence by stage was investigated. Appropriate systolic blood pressure control was defined as below 140/90 based on the mean of the two latest readings, in individuals with CKD, according to NICE guidelines [14]. For patients with urinary albumin creatinine ratio $>70 \mathrm{mg} / \mathrm{mmol}$, BP targets were more stringent, $<130 / 80 \mathrm{mmHg}$ [25]. As we were interested in modifiable lifestyle risk factor management, current smoking status and BMI were included in the analysis.

\section{Covariates}

We examined the following factors: age, gender, ethnicity, deprivation (Index of Multiple Deprivation 2015), and selected comorbidities likely to influence SBP control including coronary heart disease (CHD), heart failure (HF), stroke and serious mental illness, (SMI). Other measured factors were: diastolic blood pressure (DBP) control, prescribed ACEIs or ARBs, calcium channel blockers (CCBs), statins, NSAIDs and COX-2 inhibitors, (COXIBs) and lifestyle factors smoking and obesity. High alcohol intake was defined as $>14$ units/week. BMI was determined according

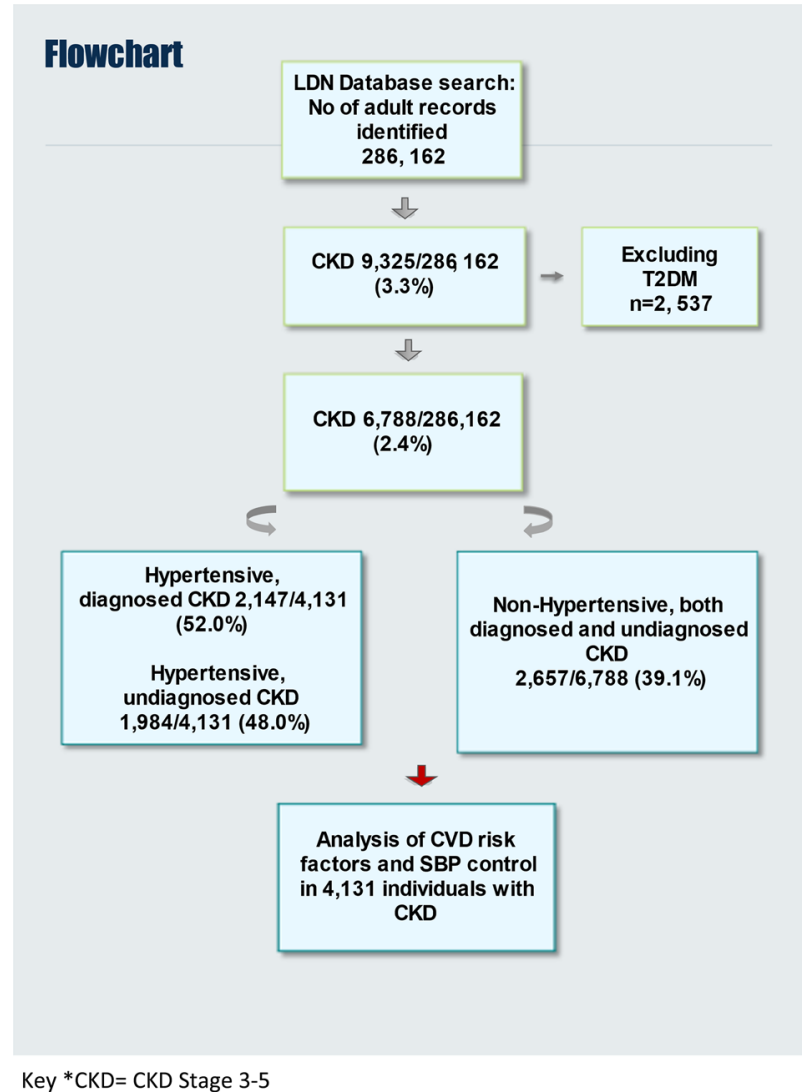

Fig. 1 Patient data selection process 
Table 2 Risk factor management in patients with hypertension and CKD (both diagnosed and undiagnosed), according to age

\begin{tabular}{|c|c|c|c|}
\hline & $\begin{array}{l}\text { CKD3 } \\
\mathrm{n}(\%)\end{array}$ & $\begin{array}{l}\text { CKD } 4 \\
\mathrm{n}(\%)\end{array}$ & $\begin{array}{l}\text { CKD } 5 \\
\mathrm{n}(\%)\end{array}$ \\
\hline \multicolumn{4}{|l|}{$\begin{array}{l}\text { Mean SBP control } \\
(<140 \mathrm{mmHg})\end{array}$} \\
\hline Age $<75$ years & $783(51.4)$ & $39(49.4)$ & $84(90.3)$ \\
\hline \multirow[t]{2}{*}{ Age $\geq 75$ years } & 739 (48.6) & $40(50.6)$ & $9(9.7)$ \\
\hline & $\mathrm{P}>0.05$ & $\mathrm{P}>0.05$ & $\mathrm{P}>0.05$ \\
\hline \multicolumn{4}{|c|}{$\begin{array}{l}\text { Mean DBP control } \\
(<90 \mathrm{mmHg})\end{array}$} \\
\hline Age $<75$ years & $1,070(47.0)$ & $50(45.0)$ & $103(86.6)$ \\
\hline \multirow[t]{2}{*}{ Age $\geq 75$ years } & $1,208(53.0)$ & $61(55.0)$ & $16(13.4)$ \\
\hline & $* *$ & $*$ & $\mathrm{P}>0.05$ \\
\hline \multicolumn{4}{|l|}{ Smoker (current) } \\
\hline Age $<75$ years & $301(64.7)$ & $18(66.7)$ & $31(96.9)$ \\
\hline \multirow[t]{2}{*}{ Age $\geq 75$ years } & $164(35.3)$ & $9(33.3)$ & $1(3.1)$ \\
\hline & $* *$ & $*$ & $\mathrm{P}>0.05$ \\
\hline \multicolumn{4}{|l|}{ Statin prescription } \\
\hline Age $<75$ years & $986(43.5)$ & $43(40.2)$ & $115(88.5)$ \\
\hline \multirow[t]{2}{*}{ Age $\geq 75$ years } & $1,280(56.5)$ & $64(59.8)$ & $15(11.5)$ \\
\hline & $* *$ & $*$ & $\mathrm{P}>0.05$ \\
\hline \multicolumn{4}{|c|}{$\mathrm{ACEI}$ or $\mathrm{ARB}$ prescription } \\
\hline Age $<75$ years & $1,456(49.4)$ & $70(50.7)$ & $135(88.8)$ \\
\hline \multirow[t]{2}{*}{ Age $\geq 75$ years } & $1,489(50.6)$ & $68(49.3)$ & $17(11.2)$ \\
\hline & $\mathrm{P}>0.05$ & $\mathrm{P}>0.05$ & $\mathrm{P}>0.05$ \\
\hline \multicolumn{4}{|c|}{$\begin{array}{l}\text { Calcium channel blocker pre- } \\
\text { scription }\end{array}$} \\
\hline Age $<75$ years & $1,435(53.5)$ & $74(52.1)$ & $134(86.4)$ \\
\hline \multirow[t]{2}{*}{ Age $\geq 75$ years } & $1,247(46.5)$ & $68(47.9)$ & $21(13.6)$ \\
\hline & $* *$ & $\mathrm{P}>0.05$ & $\mathrm{P}>0.05$ \\
\hline \multicolumn{4}{|c|}{$\begin{array}{l}\text { Overweight and obese } \\
\left(\text { BMI } \geq 25 \mathrm{~kg} / \mathrm{m}^{2}\right)\end{array}$} \\
\hline Age $<75$ years & $1,543(55.3)$ & $54(50.5)$ & $103(85.8)$ \\
\hline \multirow[t]{2}{*}{ Age $\geq 75$ years } & $1,249(44.7)$ & $53(49.5)$ & $17(14.2)$ \\
\hline & $* *$ & $\mathrm{P}>0.05$ & $\mathrm{P}>0.05$ \\
\hline
\end{tabular}

P-values comparing age $<75$ years and $\geq 75$ years in each category (column totals by age-group), respectively

$H T$ hypertension, $C K D$ chronic kidney disease, $S B P$ systolic blood pressure, $D B P$ diastolic blood pressure, $B M I$ body mass index, $A C E I$ angiotensin-converting-enzyme inhibitor use, $A R B$ angiotensin receptor blocker use, $C C B$ calcium channel blocker use

$* \mathrm{P}<0.05$

$* * \mathrm{P}<0.001$

to the World Health Organization (WHO) classification [26]. Ethnicity was self-reported and aggregated into 7 categories: White, African, Black Caribbean, South Asian, Chinese, Other, and Non-stated. Proteinuria measurements were incomplete and therefore were not included.

The primary outcome was systolic blood pressure control; the secondary outcome was CVD risk factor control in patients with CKD.

\section{Analysis}

A cross-sectional study design was used to describe demographic factors, comorbidities, and other interventions considered as being potentially effective (prescribing of statins, ACEI or ARBs) associated with hypertension status. Analysis was stratified by CKD Stage. Differences between categorical variables were assessed using Pearson's chi-squared test $\left(x^{2}\right)$ (Tables 1 and 2, Table S2, and Table S3). A twosided $\mathrm{p}$ value $<0.05$ was considered statistically significant.

Partially adjusted (adjusted for age-group and gender) and fully adjusted (adjusted for age-group, gender, and all other covariates are included in Table 3) logistic regression was conducted to examine the association between systolic blood pressure control in hypertensive CKD patients with demographic factors, selected comorbidities and treatments recommended by the NICE guidelines for cardiovascular risk management in CKD patients (Table 3 and Table S4). A twosided $p$ value $<0.05$ was considered statistically significant.

We excluded anti-hypertensive pharmacotherapy from the logistic regression approach due to ethnicity-guided prescribing, as we had already adjusted for ethnicity. The analysis adjusted for demographic and life-style factors and comorbidities in the final model. All analyses were conducted using STATA 15.

\section{Results}

\section{Descriptive characteristics of the study population}

Figure 1 shows the flowchart of how patient were selected. The population consisted of 286,162 adults followed in 47/49 GP practices in Lambeth 4131 patients out of 286,162 individuals (1.4\%) had CKD (both diagnosed and undiagnosed) and hypertension, nearly half of them (48\%, $\mathrm{n}=1984$ ) had undiagnosed CKD, as defined by eGFR $<60$ $\mathrm{ml} / \mathrm{min}$ in at least two determinations, without a recorded $\mathrm{CKD}$ diagnosis. Figure $\mathrm{S} 1$ illustrates the prevalence of CKD in the different age groups in individuals with concurrent hypertension. Figure S2 shows the relationship between age and CKD and hypertension, whose prevalence is rising steeply after 60 years.

\section{CVD risk factors and comorbidities (Tables 1, 2)}

The majority of individuals with CKD were aged $>75$ years. Achievement of systolic blood pressure targets was sub-optimal (60.2\% vs. $77.0 \%)$, both in patients with hypertensive without acknowledged and coded hypertension.

Table S3 shows CKD Stage and measured eGFR according to demographic variables. The prevalence of hypertensive CKD in stage 3 was higher in females than males 
Table 3 Multivariable regression (MVR) Associations with Mean SBP control in Hypertensive CKD (nondiabetic) adults

\begin{tabular}{|c|c|c|}
\hline & Univariable $\mathrm{OR}^{1}, 95 \% \mathrm{CI}$ & Multivariable $\mathrm{OR}^{2}, 95 \% \mathrm{CI}$ \\
\hline \multicolumn{3}{|l|}{ Age (years) } \\
\hline$<50$ & Ref. & Ref. \\
\hline $50-59$ & $1.31(0.96-1.77)$ & $1.03(0.65-1.62)$ \\
\hline $60-69$ & $1.25(0.94-1.68)$ & $0.48(0.31-0.76)^{* *}$ \\
\hline $70-79$ & $1.14(0.88-1.50)$ & $0.41(0.26-0.62)^{* *}$ \\
\hline 80-89 & $0.96(0.73-1.26)$ & $0.29(0.19-0.45) * *$ \\
\hline$>90$ & $1.05(0.74-1.51)$ & $0.34(0.20-0.58)^{* *}$ \\
\hline Gender (male) & $1.06(0.94-1.21)$ & $0.99(0.82-1.20)$ \\
\hline \multicolumn{3}{|l|}{ IMD quintile } \\
\hline 1.00 least deprived & Ref. & Ref. \\
\hline 2.00 & $0.93(0.78-1.12)$ & $0.96(0.73-1.27)$ \\
\hline 3.00 & $1.00(0.82-1.23)$ & $0.93(0.69-1.25)$ \\
\hline 4.00 & $0.99(0.81-1.20)$ & $0.97(0.73-1.30)$ \\
\hline 5.00 most deprived & $1.00(0.82-1.21)$ & $0.93(0.69-1.23)$ \\
\hline \multicolumn{3}{|l|}{ Ethnicity } \\
\hline White & Ref. & Ref. \\
\hline Black African & $0.80(0.65-0.97)$ & $0.74(0.55-0.99)^{*}$ \\
\hline Black Caribbean & $0.82(0.70-0.96)$ & $1.03(0.81-1.30)$ \\
\hline Asian & $1.04(0.79-1.36)$ & $1.29(0.81-2.04)$ \\
\hline Chinese & $0.72(0.36-1.44)$ & $0.82(0.29-2.34)$ \\
\hline Other & $1.78(1.03-3.07)$ & $1.10(0.54-2.25)$ \\
\hline Non-stated & $1.06(0.67-1.67)$ & $1.28(0.70-2.36)$ \\
\hline \multicolumn{3}{|l|}{ Lifestyle and risk factors } \\
\hline DBP control & $12.45(9.04-17.15)$ & $12.81(8.52-19.26)^{* *}$ \\
\hline Coded CKD3-5 & $1.11(0.97-1.26)$ & $1.37(1.13-1.65)^{* *}$ \\
\hline $\mathrm{BMI}>25 \mathrm{~kg} / \mathrm{m}^{2}$ & $0.81(0.69-0.95)$ & $0.80(0.65-1.00)^{*}$ \\
\hline Current smoker & $0.91(0.74-1.12)$ & $0.77(0.57-1.04)$ \\
\hline Alcohol > 14units/week & $0.63(0.30-1.32)$ & $1.64(0.52-5.22)$ \\
\hline \multicolumn{3}{|l|}{ History of comorbidities } \\
\hline Stroke & $1.06(0.86-1.32)$ & $1.08(0.78-1.51)$ \\
\hline Heart failure & $1.53(1.23-1.89)$ & $1.94(1.38-2.74)^{* *}$ \\
\hline CHD & $1.33(1.12-1.58)$ & $1.35(1.03-1.77)^{*}$ \\
\hline SMI & $1.64(1.15-2.32)$ & $2.06(1.18-3.61)^{*}$ \\
\hline
\end{tabular}

CKD includes both diagnosed and undiagnosed CKD Stage 3-5

$S M I$ serious mental illness, $C H D$ coronary heart disease, $I M D$ index of multiple deprivation, $B M I$ body mass index, $C K D$ chronic kidney disease, $D B P$ diastolic blood pressure, $S B P$ systolic blood pressure

$* \mathrm{P}<0.05$

$* * \mathrm{P}<0.001$

${ }^{1}$ Adjusted for age and gender

${ }^{2}$ Adjusted for all baseline covariates in the table
( $16.1 \%$ vs $12.9 \%, p<0.001)$, but prevalence of hypertensive CKD in stage 5 was higher in males than females $(1.2 \%$ vs $0.6 \%, \mathrm{p}<0.001$.)

\section{BP control}

The proportion of patients who achieved the SBP target was similar in pateints younger or older than 75 years (61.3\% versus 59.1\%). Achievement of the systolic blood pressure target $(<140 \mathrm{mmHg})$ was lower in CKD 3-5 in patients of Black African ethnicity compared with patients of White ethnicity (55.7\% and $60.5 \%$, respectively, $\mathrm{p}=0.02$ ), but was not different when compared with Black Caribbean patients $(58.8 \%, \mathrm{p}=0.5)$ (Table S2). 


\section{Pharmacotherapy}

Three hundred nine/4,131 (7.4\%) individuals with diagnosed HT and CKD were not taking any of the anti-hypertensive medications considered in our study. Statins were under-prescribed, and this was more marked in hypertensive vs. non hypertensive CKD patients, receiving statins respectively in $54.9 \%$ vs $23.3 \%$ of the cases $(\mathrm{P}<0.001)$ (Table 1$)$, the gap was especially important for patients under 75 years (47.8 vs $62.0 \%, \mathrm{p}<0.001)$.

\section{Logistic regression}

Multivariable logistic regression analyses of factors associated with systolic blood pressure control are shown in Table 3. The multivariabel logistic regression analyses revealed the following significant associations with SBP control: diastolic blood pressure control (adjusted odds ratio 12.81 (95\% CI: 8.52-19.26)) and the following comorbidities: heart failure (OR 1.94), coronary heart disease (OR 1.35), serious mental illness (OR 2.06). Conversely, diagnostic CKD coding was associated with improved SBP control. Factors associated with poor systolic blood pressure control were age $\geq 60$ years and Black African ethnicity.

\section{Discussion}

The first important finding in this large cohort of patients followed up in 47 GP practices in Lambeth SE London is the high prevalence of both underdiagnosed CKD (nearly 50\%) and underdiagnosed hypertension (23\%) in patients with CKD. Furthermore, systolic blood pressure control was below target in a relevant percentage of cases. Multivariable logistic regression revealed that factors associated with improved systolic blood pressure control in CKD included diastolic blood pressure control, and the presence of comorbidities that are probably associated with a more strict patient control; these include serious mental illness, history of cardiovascular co-morbidities, CKD diagnostic coding, and age $<60$ years. African ethnicity and obesity were conversely associated with poorer systolic blood pressure control. The finding of a better blood pressure control in patients with serious mental illness is important as this group is at increased risk of cardiovascular mortality [27].

This is a study of a well characterized ethnically and socially diverse population in 47 GP practices in Lambeth SE London, with extensive recording of clinical data, medication, and patients' characteristics. Our large database allowed us to undertake a detailed exploration of risks in individuals with CKD and hypertension, sorting them by ethnicity, and adding important information on CKD prevalence and management in Black African and Black Caribbean sub-groups.

The study has however several limitations and these limitations are mostly shared by observational real life studies; these include diagnostic misclassifications, lack of data on medication adherence and patients' choices, missing data (e.g., proteinuria) and unmeasured confounders. We tried to correct some misclassifications by revising CKD codes, using MDRD ethnicity-adjusted eGFR values. Furthermore, blood pressure readings were based on the mean of the last two recorded measurements after CKD diagnosis, and BP trajectories may provide better longer-term estimates of BP control in future studies. Currently, smoking cessation services are provided by an external provider, and are poorly coded in our database, and so this information was not included in this study.

Although prescriptions were well captured, we did not have estimates of adherence to the prescribed treatments, which may be modulated by ethnicity and CKD status. Lastly, we were also unable to look at longitudinal outcomes, including morbidity and mortality and start of renal replacement therapy.

We found that the overall prevalence of $\mathrm{CKD} \geq 3$ (both diagnosed and undiagnosed) amongst adults was 3.3\%, which is lower than the national average of $4.3 \%$ [9]. As the Lambeth population is much younger; data from Lambeth DataNet suggests $45 \%$ of the Lambeth population are aged between 18 and 39 years old, differences in population demographics and/or CKD prevalence in different ethnic groups are likely to explain this variation [28]. However, we also noted CKD is underdiagnosed in general practice, similar to national findings in England [9]. Due to the high prevalence of hypertension-related kidney diseases, we would expect most individuals with CKD to have previously diagnosed hypertension. Our study found that in our non-diabetic CKD cohort 4131 individuals out of 6788 cases with CKD (61.9\%) had been diagnosed with hypertension. Of 3142 cases with sufficient BP readings, $1994(63.5 \%)$ reached their systolic blood pressure target (Table 1). However, we found that $23 \%$ of CKD patients not recorded as with hypertension had mean systolic blood pressure $>140 \mathrm{mmHg}$, and, importantly, the prevalence of diagnosed heart failure in this group was $3.7 \%$, clinically relevant, even if lower than the prevalence of $8.3 \%$ found in CKD patients recorded as hypertensive $(\mathrm{P}<0.05)$.

Obesity and poor blood pressure control are key risk factors for CKD development [22, 23]. However, differences in CKD prevalence by stage and progression cannot be attributed to BP control alone, and disease progression is likely to be multifactorial. Blood pressure remains one of the key determinants of progression, even if not the only one, and our study shows that current BP targets are not being met in a large proportion of the patients. This observation is of 
clinical importance, considering also that large studies, like SPRINT [29] and ACCORD-BP [30] suggested that even lower BP targets should be adopted [31]. The STOP ACEI trial, which completed recruiting in 2019, will probably identify whether the use of ACEIs and ARBs is beneficial in Stage 4 and 5 CKD, allowing us modulating these treatments in our population [32]. The NICE guidelines recommend an extensive use of statins in CKD for the prevention of cardiovascular diseases and suggest seeking specialist advice before increasing statin doses in patients with eGFR at or lower than $30 \mathrm{~mL} / \mathrm{min} / 1.73 \mathrm{~m}^{2}$ [14]. The latest KDIGO guideline does not recommend initiation of statins in CKD 5 patients on dialysis (following SHARP and 4-D trials) [33], although this may change in future. Even with these caveats, the use of statins was relatively low in our population, thus suggesting that there may be room for improvement in this regard.

Raising awareness of the importance of risk factor management in primary care includes more rigorous management of systolic blood pressure, together with a series of potentialy beneficial actions on CKD progression, including smoking cessation, which however was not analysed in our study, and correction of overweight and obesity tailoring pharmacotherapy (statins, ACEI/ARB) is also an important tool to prevent CKD development and slow progression. Public health strategies, and education about CKD are important to minimise preventable morbidity and mortality [34]. Subsequently, improved coding linked to eGFR and proteinuria (no longer incentivised in QOF) may offer opportunities for improving data standards, overall supporting better care [35].

\section{Conclusions}

The main result of this study was to find a high prevalence of underdiagnosed CKD and underdiagnosed hypertension in patients with CKD. In CKD patients with hypertension, poorly controlled blood pressure may contribute to CKD progression and increase the risk of heart failure. Our study shows that there is an unmet need to improve CKD detection and management (relative underdiagnosis of CKD Stage 3 ) in high-risk groups ( $<75$ years, Black African, Asian, and "Other" ethnic groups). In our study, management of modifiable risk factors was found to be sub-optimal, particularly in younger patients. This applies also to pharmacotherapy (anti-hypertensives, ACEIs/ARBs, statins), which was found to be under prescribed. Improving risk factor management and establishing public health educational strategies should be a priority, as these interventions may help prevent CKD diagnosis or delay disease progression.
Supplementary Information The online version contains supplementary material available at https://doi.org/10.1007/s40620-021-01149-0.

Acknowledgements This research was supported by the National Institute for Health Research (NIHR) Biomedical Research Centre at Guy's and St Thomas' NHS Foundation Trust and King's College London. The views expressed are those of the author(s) and not necessarily those of the NHS, the NIHR or the Department of Health.

Author contributions $\mathrm{MM}$ and DN contributed to the idea generation and protocol development. EMC and SD prepared the data for analysis, EMC and MM performed the statistical analyses. EMC and MM interpreted study results, EMC and MM had primary responsibility in writing the manuscript. MA, DN, EA and CS also contributed to manuscript writing. All authors critically reviewed the manuscript.

Funding This work was undertaken as part of the KCL MPH dissertation programme.

\section{Declarations}

Conflict of interest The authors have no conflicts of interest to declare that are relevant to the content of this article.

Ethical statement Ethical approval for LDN was provided by The Lambeth DataNet Steering Group, a sub-group of Lambeth CCG. Information Governance (IG) was approved by the IG team at the Commissioning Support Unit and Lambeth CCG's Caldicott Guardian.

Open Access This article is licensed under a Creative Commons Attribution 4.0 International License, which permits use, sharing, adaptation, distribution and reproduction in any medium or format, as long as you give appropriate credit to the original author(s) and the source, provide a link to the Creative Commons licence, and indicate if changes were made. The images or other third party material in this article are included in the article's Creative Commons licence, unless indicated otherwise in a credit line to the material. If material is not included in the article's Creative Commons licence and your intended use is not permitted by statutory regulation or exceeds the permitted use, you will need to obtain permission directly from the copyright holder. To view a copy of this licence, visit http://creativecommons.org/licenses/by/4.0/.

\section{References}

1. Levey AS, Coresh J (2012) Chronic kidney disease. The Lancet 379:165-180. https://doi.org/10.1016/S0140-6736(11)60178-5

2. Webster AC, Nagler EV, Morton RL, Masson P (2017) Chronic Kidney Disease. The Lancet 389:1238-1252. https://doi.org/10. 1016/S0140-6736(16)32064-5

3. Gansevoort RT (2019) Too much nephrology? The CKD epidemic is real and concerning. A PRO view. Nephrol Dial Transplant 34:577-580. https://doi.org/10.1093/ndt/gfy330

4. Public Health England (2014) Chronic Kidney Disease (CKD) prevalence model. https://assets.publishing.service.gov.uk/gover nment/uploads/system/uploads/attachment_data/file/612303/ ChronickidneydiseaseCKDprevalencemodelbriefing.pdf

5. Nguyen NTQ, Cockwell P, Maxwell AP et al (2018) Chronic kidney disease, health-related quality of life and their associated economic burden among a nationally representative sample of 
community dwelling adults in England. PLoS ONE 13:e0207960. https://doi.org/10.1371/journal.pone.0207960

6. NHS (2021) NHS Digital Quality and Outcomes Framework (QOF), enhanced services and core contract extraction specifications (business rules). In: NHS Digit. https://digital.nhs.uk/dataand-information/data-collections-and-data-sets/data-collections/ quality-and-outcomes-framework-qof. Accessed 23 Apr 2021

7. Fat LN, Mindell J, Roderick P (2017) Health Survey for England 2016 Kidney and liver disease

8. Nichols GA, Déruaz-Luyet A, Hauske SJ, Brodovicz KG (2018) The association between estimated glomerular filtration rate, albuminuria, and risk of cardiovascular hospitalizations and all-cause mortality among patients with type 2 diabetes. J Diabetes Complications 32:291-297. https://doi.org/10.1016/j.jdiacomp.2017. 12.003

9. Nitsch D, Caplin B, Hull S, Wheeler D (2017) National Chronic Kidney Disease Audit: National Report (Part 1)

10. Hull S, Dreyer G, Badrick E et al (2011) The relationship of ethnicity to the prevalence and management of hypertension and associated chronic kidney disease. BMC Nephrol 12:41. https:// doi.org/10.1186/1471-2369-12-41

11. Martins D, Agodoa L, Norris KC (2012) Hypertensive chronic kidney disease in African Americans: strategies for improving care. Cleve Clin J Med 79:726-734. https://doi.org/10.3949/ccjm. 79a.11109

12. Hanratty R, Chonchol M, Miriam Dickinson L et al (2010) Incident chronic kidney disease and the rate of kidney function decline in individuals with hypertension. Nephrol Dial Transplant 25:801-807. https://doi.org/10.1093/ndt/gfp534

13. Kawar B, Kossi ME, Patel R, et al (2009) Practical approaches to the diagnosis and management of common nephrological problems. In: El Nahas (ed) Chronic Kidney Disease: A practical guide to understanding and management. Oxford University Press

14. NICE (2020) Chronic kidney disease. https://cks.nice.org.uk/topics/chronic-kidney-disease/. Accessed 23 Apr 2021

15. Fraser SD, Roderick PJ, Mcintyre NJ et al (2013) Suboptimal blood pressure control in chronic kidney disease stage 3: baseline data from a cohort study in primary care. BMC Fam Pract 14:88. https://doi.org/10.1186/1471-2296-14-88

16. Hemmelgarn BR, Manns BJ, Lloyd A et al (2010) Relation between kidney function, proteinuria, and adverse outcomes. JAMA 303:423-429. https://doi.org/10.1001/jama.2010.39

17. Hallan SI, Ritz E, Lydersen S et al (2009) Combining GFR and Albuminuria to Classify CKD Improves Prediction of ESRD. J Am Soc Nephrol JASN 20:1069-1077. https://doi.org/10.1681/ ASN.2008070730

18. Lopez-Giacoman S, Madero M (2015) Biomarkers in chronic kidney disease, from kidney function to kidney damage. World J Nephrol 4:57-73. https://doi.org/10.5527/wjn.v4.i1.57

19. Bell EK, Gao L, Judd S et al (2012) Blood Pressure Indexes and End-Stage Renal Disease Risk in Adults With Chronic Kidney Disease. Am J Hypertens 25:789-796. https://doi.org/10.1038/ ajh. 2012.48

20. Klag MJ, Whelton PK, Randall BL et al (1996) Blood pressure and end-stage renal disease in men. N Engl J Med 334:13-18. https://doi.org/10.1056/NEJM199601043340103

21. Young JH, Klag MJ, Muntner P et al (2002) Blood Pressure and Decline in Kidney Function: Findings from the Systolic Hypertension in the Elderly Program (SHEP). J Am Soc Nephrol 13:27762782. https://doi.org/10.1097/01.ASN.0000031805.09178.37
22. Chang AR, Grams ME, Ballew SH et al (2019) Adiposity and risk of decline in glomerular filtration rate: meta-analysis of individual participant data in a global consortium. BMJ. https://doi.org/10. 1136/bmj.k5301

23. Tsai W-C, Wu H-Y, Peng Y-S et al (2016) Risk factors for development and progression of chronic kidney disease. Medicine. https:// doi.org/10.1097/MD.0000000000003013

24. Klimontov VV, Korbut AI (2019) Albuminuric and non-albuminuric patterns of chronic kidney disease in type 2 diabetes. Diabetes Metab Syndr Clin Res Rev 13:474-479. https://doi.org/10.1016/j. dsx.2018.11.014

25. NICE (2015) Chronic kidney disease in adults: assessment and management. Clinical guidelines [CG182]. https://www.nice.org.uk/guida nce/cg182/chapter/1-Recommendations. Accessed 23 Apr 2021

26. WHO (2021) Body mass index-BMI. https://www.euro.who.int/ en/health-topics/disease-prevention/nutrition/a-healthy-lifestyle/ body-mass-index-bmi. Accessed 23 Apr 2021

27. Correll CU, Solmi M, Veronese N et al (2017) Prevalence, incidence and mortality from cardiovascular disease in patients with pooled and specific severe mental illness: a large-scale metaanalysis of 3,211,768 patients and 113,383,368 controls. World Psychiatry 16:163-180. https://doi.org/10.1002/wps.20420

28. Kim LG, Cleary F, Wheeler DC et al (2018) How do primary care doctors in England and Wales code and manage people with chronic kidney disease? Results from the National Chronic Kidney Disease Audit. Nephrol Dial Transplant 33:1373-1379. https:// doi.org/10.1093/ndt/gfx280

29. Ambrosius WT, Sink KM, Foy CG et al (2014) The design and rationale of a multicenter clinical trial comparing two strategies for control of systolic blood pressure: the Systolic Blood Pressure Intervention Trial (SPRINT). Clin Trials Lond Engl 11:532-546. https://doi.org/10.1177/1740774514537404

30. Papademetriou V, Zaheer M, Doumas M et al (2016) Cardiovascular outcomes in action to control cardiovascular risk in diabetes: impact of blood pressure level and presence of kidney disease. Am J Nephrol 43:271-280. https://doi.org/10.1159/000446122

31. Collard D, Brouwer TF, Olde Engberink RHG et al (2020) Initial Estimated Glomerular Filtration Rate Decline and Long-Term Renal Function During Intensive Antihypertensive Therapy. Hypertens Dallas Tex 75:1205-1212. https://doi.org/10.1161/ HYPERTENSIONAHA.119.14659

32. Bhandari S, Ives N, Brettell EA et al (2016) Multicentre randomized controlled trial of angiotensin-converting enzyme inhibitor/angiotensin receptor blocker withdrawal in advanced renal disease: the STOP-ACEi trial. Nephrol Dial Transplant 31:255-261. https://doi.org/10.1093/ndt/gfv346

33. KDIGO (2013) Lipids in CKD. https://kdigo.org/guidelines/lipidsin-ckd/. Accessed 23 Apr 2021

34. Carrero JJ, Hecking M, Chesnaye NC, Jager KJ (2018) Sex and gender disparities in the epidemiology and outcomes of chronic kidney disease. Nat Rev Nephrol 14:151-164. https://doi.org/10. 1038/nrneph.2017.181

35. Hull SA, Rajabzadeh V, Thomas $N$ et al (2019) Improving coding and primary care management for patients with chronic kidney disease: an observational controlled study in East London. Br J Gen Pract 69:e454-e461. https://doi.org/10.3399/bjgp19X704105

Publisher's Note Springer Nature remains neutral with regard to jurisdictional claims in published maps and institutional affiliations. 